\title{
Association of Spring Pruning Practices with Severity of Powdery Mildew and Downy Mildew on Hop
}

David H. Gent, United States Department of Agriculture-Agricultural Research Service (USDA-ARS), Forage Seed and Cereal Research Unit, and Department of Botany and Plant Pathology, Oregon State University, Corvallis 97331; Mark E. Nelson and Gary G. Grove, Department of Plant Pathology, Washington State University Irrigated Agriculture Research and Extension Center, Prosser 99350; Walter F. Mahaffee, USDA-ARS, Horticultural Crops Research Laboratory, and Oregon State University, Department of Botany and Plant Pathology 97330; William W. Turechek, USDA-ARS, U. S. Horticultural Research Laboratory, Fort Pierce, FL, 34945; and Joanna L. Woods, Department of Crop and Soil Science, Oregon State University 97331

\begin{abstract}
Gent, D. H., Nelson, M. E., Grove, G. G., Mahaffee, W. F., Turechek, W. W., and Woods, J. L. 2012. Association of spring pruning practices with severity of powdery mildew and downy mildew on hop. Plant Dis. 96:1343-1351.

Downy mildew (caused by Pseudoperonospora humuli) and powdery mildew (caused by Podosphaera macularis) are important diseases of hop in the Pacific Northwest United States, and cultural practices may affect the severity of both diseases. The association of spring pruning quality and timing with severity of downy mildew and powdery mildew was assessed through analysis of survey data collected from commercial hop yards in Oregon and Washington. Among 149 hop yards surveyed, the most common pruning method was chemical desiccation (48\% of yards), mechanical pruning (23\%), or a combination of these practices $(15 \%)$. The quality of pruning was assessed using a threecategory ordinal scale ("excellent", "moderate", or "poor") based on the amount of foliage remaining on plants following pruning. Excellent pruning quality was attained more often in yards pruned twice (74.6 to $82.1 \%$ of yards) versus once (33.8\% of yards), independent of pruning method. Seasonal severity of downy mildew in Oregon increased approximately twofold with reduction in pruning quality from excellent to moderate to poor. Pruning quality was not significantly related to levels of powdery mildew on leaves or cones in Oregon. Under more severe disease pressure in Washington, however, seasonal severity of powdery mildew on leaves and the incidence of cones with powdery

mildew were significantly greater in yards that had poor pruning compared with excellent pruning. Moreover, yards that had excellent pruning quality received, on average, 1.1 to 1.5 fewer fungicide applications per season for downy mildew or powdery mildew compared with yards that had moderate or poor pruning quality. This savings was associated with delayed initiation of the first application by 7.5 to 14.2 days in yards with excellent pruning quality. Replicated experiments in commercial yards in Oregon quantified the effect of delaying pruning timing 5 to 21 days compared with growers' standard practices on the diseases and yield. Downy mildew suppression by delayed pruning was dependent on cultivar and year of sampling, being significantly reduced fivefold only in 'Willamette' in 2007. Severity of powdery mildew and cone yield was similar between plots that received the delayed or standard pruning timing treatments. Collectively, these studies emphasize that early spring sanitation measures are associated with reduced primary inoculum and are critically important for managing both downy mildew and powdery mildew. A savings of at least one fungicide application per year appears achievable when spring pruning is conducted thoroughly and slightly delayed compared with growers' current practices.
\end{abstract}

Cultural disease management practices are actions that involve the manipulation of the plant, its components, crop refuse, and the environment to reduce or prevent disease $(5,26,31,34)$. In hop ( $\mathrm{Hu}$ mulus lupulus L.), cultural practices are an important component of integrated management of the two most important foliar diseases of this crop: downy mildew, caused by Pseudoperonospora humuli; and powdery mildew, caused by Podosphaera macularis $(21,22,27,29)$. Hop is a long-lived perennial plant that produces annual, herbaceous shoots from overwintering buds formed on new wood or from established wood deeper in the root system (30). Both pathogens have a phase of their lifecycle that involves peren-

\section{Corresponding author: D. H. Gent, E-mail: gentd@onid.orst.edu}

Mention of a trademark, proprietary product, or vendor does not constitute a guarantee or warranty of the product by the United States Department of Agriculture and does not imply its approval to the exclusion of the products or vendors that may also be suitable.

* The $e$-Xtra logo stands for "electronic extra" and indicates that a supplementary figure is available online.

Accepted for publication 9 April 2012.

http://dx.doi.org/10.1094/PDIS-01-12-0084-RE

This article is in the public domain and not copyrightable. It may be freely reprinted with customary crediting of the source. The American Phytopathological Society, 2012. nation in or on buds formed on new wood during the previous season. In the case of Pseudoperonospora humuli, this is thought to occur via systemic infection of the root system and subsequent invasion of crown buds during autumn and winter (2,32). Buds invaded earliest and most severely can be killed, whereas buds with less severe colonization by the pathogen are reported to survive winter to produce systemically infected shoots (termed "spikes" due to their resemblance to a wheat spike) in spring (2). These spikes are a primary source of inoculum to initiate downy mildew epidemics. Oospores are frequently found in leaves, shoots, and cones with downy mildew, although the contribution of oosporic inoculum to epidemic development has largely been discounted because definitive evidence of oospore germination and infection in the field is lacking (29). Systemic infections are generally accepted as a key source of primary inoculum $(2,16,29)$.

In an analogous but biologically distinct process, Podosphaera macularis may infect crown buds during the preceding season, persisting as asexual mycelia or generally less common, sexually derived cleistothecia in and on buds (19). After dormancy and resumption of host growth in the following early spring, some proportion of these infected buds give rise to shoots colonized by the fungus and are referred to as "flag shoots" (19). Bud perennation is the only known means of overwintering of the pathogen in the Pacific Northwest region of the United States, presumably because only one mating type of the fungus is present or prevalent in the region (8).

Early-season pruning of hop plants is conducted for horticultural purposes so that shoot growth is synchronized to optimize vigor 
and yield, with the optimal timing generally being cultivar specific (25). Hop is a perennial that produces annual shoots, and spring pruning can eliminate buds produced in the previous season and young shoots if conducted mechanically, or only shoots if conducted chemically. Pruning may occur before or after the initial growth begins and may be accomplished by mechanical means, chemical desiccation of shoots, or, less commonly, by other methods such as propane flaming of shoots. Depending on the timing and method of pruning, new, young shoots and surface crown buds may be removed. The method and timing of pruning is determined relatively early in the season, well before the presence and severity of powdery mildew and downy mildew in a particular hop yard is known. Because of the importance of infected buds as a source of primary inoculum, pruning during dormancy or just after bud break could significantly reduce initial inoculum and impact epidemic development.

Previous studies have reported an association between the timing and thoroughness ("quality") of pruning and the severity of downy and powdery mildews. In Europe, delayed spring pruning suppressed downy mildew but yield was also reduced if pruning was conducted too late (13). Skotland and Johnson (33) discussed a similar strategy of delayed spring pruning to escape downy mildew in the semiarid environment in central Washington State, although data from empirical studies were not presented. Royle (27) stated that, in England, powdery mildew became active earlier in the season with the shift to chemical desiccation of hop shoots in place of mechanical methods that were used previously for spring pruning. This phenomenon was attributed to a higher prevalence of bud perennation of the pathogen because buds formed on new wood were not physically removed with chemical desiccation of shoots, whereas mechanical pruning (which was performed during late winter) did physically eliminate these buds. Turechek et al. (36) presented data from surveys of commercial hop yards in Washington State that indicated an association between the amount of foliage remaining after pruning and the incidence of powdery mildew on leaves during spring, indicating that pruning quality (in addition to pruning method) is important for management of powdery mildew.

Collectively, these studies indicated that the timing and thoroughness of spring pruning are important considerations for managing both diseases. Optimal pruning dates for hop cultivars grown in the Pacific Northwest have not been described precisely, and it is unclear how pruning timing affects the severity of downy mildew and powdery mildew in this environment. It is known, however, that the effectiveness of sanitation measures is related to epidemic length (20). Although there are some indications that thorough pruning is associated with reduced incidence of powdery mildew during spring (36), the effect of this sanitation practice on overall epidemic development has not been fully documented.

The objective of this research was to quantify the association of thoroughness of pruning on the seasonal development of downy and powdery mildew and identify specific practices associated with thoroughness of pruning. We also sought to quantify the effect of delayed pruning timing on development of both diseases as well as yield.

\section{Materials and Methods}

Field locations and description. Commercial hop yards in Oregon and Washington were sampled for downy mildew, powdery mildew, or both during 2000 and annually from 2005 to 2010 . Downy mildew studies were conducted only in Marion County, OR, where most commercial hop production occurs in the state. This region has a mild, marine west-coast climate with cool, wet winters and warm, dry summers. Powdery mildew studies were conducted in both Oregon and Washington. In Washington, the hop yards were located in the south-central portion of the state in Yakima Valley. This region is semiarid, typically with warm to hot summers and infrequent rain. For each of the hop yards included in this study, the cooperating growers provided production records with information on cultivar, pruning practices, date of spring pruning, and pesticide applications. Pesticide records were available for 104 hop yards included in the downy mildew studies and 79 hop yards included in the powdery mildew studies. Hop yards included in this study ranged from about 3 to 20 ha and ranged in age from 2 to about 20 years.

Disease assessments. Downy mildew. In Oregon, downy mildew occurs annually in most hop yards. Sampling to determine the incidence of plants with basal shoots with downy mildew was conducted as described by Gent et al. (4). In brief, yards were assessed every 2 to 3 weeks beginning in early to mid-March and continuing through early to mid-July using a stratified sampling approach. Each yard was divided into strata by dividing the number of rows by 20 (rounded up to the nearest integer). In each of at least two strata, a single row was selected arbitrarily and the first 50 or 100 plants (unless the row contained fewer than this number of plants) along the row were inspected and the number of diseased shoots on each plant was recorded. Disease assessments were conducted by visually examining all shoots on each plant for signs and symptoms characteristic of shoot infection by the downy mildew pathogen in the basal foliage; specifically, chlorosis and shortened internodes. A shoot was positively identified as having downy mildew if the diagnostic sporulation of the pathogen was present on an abaxial leaf surface. The number of shoots present on a given plant varied depending on cultivar and time of year but ranged from approximately 10 at the first assessment to greater than 100 in July. From this disease density data, the incidence of hop plants with downy mildew was calculated for each sampling date. Disease assessments were conducted at least four times in every hop yard.

In total, 110 location-years of hop yards were assessed for downy mildew; the number of yards assessed in a given year ranged from 6 to 27. The cultivars (number of yards) included in this study were 'Cascade' $(n=2)$, 'Centennial' $(n=4)$, 'Crystal' $(n$ $=2)$, 'Liberty' $(n=2)$, 'Mt. Hood' $(n=2)$, 'Nugget' $(n=46)$, 'Super Galena' $(n=1)$, 'Glacier' $(n=3)$, 'Vanguard' $(n=2)$, and 'Willamette' $(n=46)$. Downy mildew susceptibility varies among the cultivars included in this study from highly susceptible (Crystal, Glacier, and Mt. Hood) to moderately resistant (Willamette) (16). All yards were sampled during at least 2 years, except for one yard each of Nugget, Super Galena, and Willamette that were sampled only during 2008 and the three yards of Glacier that were sampled only during 2005.

Powdery mildew. Sampling approaches for powdery mildew were based on the methods described by Turechek and Mahaffee (35) for leaves and Gent et al. (6) for cones. Disease incidence on both leaves and cones was assessed using a stratified sampling approach as above and modified as described below. Incidence of powdery mildew on leaves was assessed in hop yards every 1 to 3 weeks beginning in May and continuing through August or early September, which is near the time of harvest. In 2000, a row in each stratum in the yard was selected for sampling. In subsequent years, only two strata in each yard were selected for sampling. In each row, 10 leaves were selected arbitrarily from each of the first 100 (Oregon) or 75 (Washington) plants along the row based on expected disease incidence (10), and each leaf was rated for presence or absence of powdery mildew based on the occurrence of visible sporulation of the fungus.

At harvest, the incidence of cones with powdery mildew was determined by sampling from the first 25 to 60 plants in a single row depending on the year of sampling. Cones were collected from lateral branches at heights of approximately 2.7, 3.7, and $5.5 \mathrm{~m}$. The cones from each plant were bulked before selecting 25 cones arbitrarily from each plant. Each selected cone was evaluated for signs of $P$. macularis with the aid of a dissecting microscope $(\times 10$ to 60) when necessary.

For powdery mildew, the total number of yards sampled and included in the analyses was 97, with 9 to 24 yards being assessed in a given year. The studies were conducted in hop yards planted to the cultivars (number of yards) 'Chelan' $(n=1)$, 'Columbus', 'Tomahawk', or 'Zeus' (dubbed "CTZ" because these cultivars are closely related and often not distinguished; $n=40)$, Glacier $(n=$ 
3), 'Perle' $(n=1)$, Vanguard $(n=2)$, and Willamette $(n=50)$. Powdery mildew susceptibility also varies among the cultivars, with CTZ, Glacier, and Chelan being highly susceptible and Vanguard and Willamette being moderately susceptible (7).

Association of pruning quality and method with disease severity. For both diseases, at least four disease assessments were conducted each season to allow for calculation of the relative area under the disease progress curve (RAUDPC). RAUDPC was calculated by the trapezoidal method and standardized by the duration of time over which disease assessments were conducted (20). For downy mildew, RAUDPC was based on the incidence of plants with downy mildew whereas, for powdery mildew, RAUDPC was calculated from the incidence of leaves with powdery mildew.

Evaluation of pruning quality was done for each of the hop yards included in this study using a simple three-point ordinal scale (36). Within a week of spring pruning, each hop yard received a pruning quality score of 1 (corresponding to excellent pruning quality) if no green leaves or stems remained immediately after pruning, 2 (moderate pruning quality) if green leaves or stems were present on some plants after pruning, or 3 (poor pruning quality) if numerous leaves and shoots were visible on each plant following pruning or if the yard was not pruned. Examples of pruning quality are shown in Supplementary Figure 1.

The relationship between pruning quality rating and severity of downy mildew or powdery mildew was assessed through mixedmodeling approaches (18). For downy mildew, the epidemic severity in a given hop yard (as measured by RAUDPC) was modeled to be a function of the independent variables pruning quality (a class variable for excellent, moderate, or poor pruning quality) and year of sampling (a class variable for each of the 7 years). These variables were considered fixed effects in the analysis.

For powdery mildew, disease data were available for both Oregon and Washington. Therefore, the epidemic severity on leaves (RAUDPC) or cones (incidence of cones with powdery mildew) was modeled to be dependent on three fixed-effect variables: pruning quality, state (Oregon or Washington), interaction of pruning qualitystate, and year of sampling. Each of these variables was considered a fixed factor. Analyses were carried out using the GLIMMIX procedure in SAS (version 9.2; SAS Institute). Model diagnostics indicated unequal residual variances among pruning quality groups (homogeneity of variance test $P \leq 0.0001$ for both powdery mildew and downy mildew). To account for these unequal variances in the analysis, heterogeneous variances between pruning quality classes were specified with the group option in GLIMMIX. Cone incidence data was not transformed based on residual diagnostics.

To associate pruning quality classes with the pruning methods utilized by the growers, the pruning quality data for both downy mildew and powdery mildew were combined. This yielded a total of 149 individual location-years where both pruning quality and pruning method were known. The hop yards surveyed in this study were pruned using various methods. For instance, some producers utilized carfentrazone-ethyl for chemical pruning, whereas others utilized paraquat. To reduce the complexity of the data, methods of pruning were grouped into defined categories: no pruning, desiccation of shoots by an herbicide (chemical pruning), physical removal of shoots and crown buds by mechanical means (mechanical pruning), mowing of shoots, propane flaming, or some combination of these practices. Because some yards received more than one application of a chemical desiccant, chemical pruning was differentiated as once versus twice. Thus, there were 10 different pruning methods that could be assigned to hop yards (Table 1).

Because some yards received two pruning treatments instead of just one, two $\chi^{2}$ tests of independence were conducted to test whether pruning quality differed for (i) pruning methods applied once versus twice and, more specifically, (ii) chemical pruning once versus twice. For the first comparison, yards receiving no pruning were excluded from the analysis. The analyses were conducted using the FREQ procedure in SAS version 9.2.

Grower fungicide spray practices. A simple summary of pesticide use patterns associated with pruning quality was conducted utilizing the pesticide sprays records provided by cooperating growers. A typical pesticide record included the date of pesticide application, trade name, and rates of the products applied. From this information, the date (day of year) of the first and last application of a product with efficacy against powdery mildew or downy mildew was recorded. In addition, the total number of applications made for a given disease was recorded. Tank-mixes of various fungicides often were made but, for simplicity, a tank-mix of two or more fungicides with efficacy against a given disease was considered one "application".

Rules were created for determining whether a particular product was used to target downy mildew, powdery mildew, or both. A pesticide application was classified as a treatment for a given disease if (i) the disease was specifically listed as controlled by the pesticide on the manufacturer's label, (ii) the disease was not listed specifically as controlled on the label but an identical active ingredient was registered for use against the disease on hop (e.g., sulfur products that claim control of an arthropod pest but not powdery mildew), or (iii) the pesticide was reported in a primary literature source to provide statistically significant control of powdery mildew or downy mildew on hop (e.g., copper applied for powdery mildew control; 28). In cases where there was ambiguity about a given product, correspondence with the cooperating grower was initiated for clarification. Pesticide records were available and summarized for all 110 hop yards utilized for downy mildew studies. For powdery mildew, 79 records in all were available and summarized for hop yards for which pruning quality ratings and disease assessment data also were available.

Table 1. Spring pruning methods of commercial hop yards surveyed in Oregon and Washington and their association with pruning quality rating class

\begin{tabular}{|c|c|c|c|c|}
\hline \multirow[b]{2}{*}{ Pruning method $^{\mathrm{a}}$} & \multicolumn{4}{|c|}{ Number of hop yards in each class (proportion of total) } \\
\hline & Excellent & Moderate & Poor & Total \\
\hline Chemical $(\times 1)$ & $6(0.04)$ & $10(0.07)$ & $17(0.11)$ & $33(0.22)$ \\
\hline Chemical $(\times 2)$ & $32(0.21)$ & $5(0.03)$ & $2(0.01)$ & $39(0.26)$ \\
\hline Mechanical & $17(0.11)$ & $10(0.07)$ & $8(0.05)$ & $35(0.23)$ \\
\hline Mechanical + chemical $(\times 1)$ & $16(0.11)$ & $5(0.03)$ & $1(0.01)$ & $22(0.15)$ \\
\hline Mowed & $1(0.01)$ & $1(0.01)$ & $0(0)$ & $2(0.01)$ \\
\hline Mowed + chemical $(\times 1)$ & $2(0.01)$ & $2(0.01)$ & $2(0.01)$ & $6(0.04)$ \\
\hline None & $0(0)$ & $0(0)$ & $4(0.03)$ & $4(0.03)$ \\
\hline Propane flamed & $0(0)$ & $1(0.01)$ & $0(0)$ & $1(0.01)$ \\
\hline Propane flamed + chemical $(\times 1)$ & $0(0)$ & $0(0)$ & $2(0.01)$ & $2(0.01)$ \\
\hline Propane flamed + mowed & $0(0)$ & $1(0.01)$ & $0(0)$ & $1(0.01)$ \\
\hline Total & $76(0.51)$ & $37(0.25)$ & $36(0.24)$ & $149(1)$ \\
\hline
\end{tabular}

${ }^{a}$ Spring pruning method was determined during surveys of commercial hop yards or from inspection of grower production records. Pruning quality was rated following growers' pruning operation, and classified as "excellent" if no green leaves or stems were present on any hop plants, "poor" if green tissue was remaining on every plant, and "moderate" otherwise. Data are from 110 hop yards in Oregon rated during 2005 to 2010 and 39 hop yards in Washington rated during 2000 and from 2005 to 2010. Chemical pruning was conducted using a herbicide desiccant (carfentrazone or paraquat) applied once $(\times 1)$ or twice $(\times 2)$. Mechanical pruning was defined as any pruning practice that physically removed new wood produced during a previous season. 
Pruning timing study. Studies were conducted during 2007 to 2009 in Oregon to assess the impact of the timing of spring pruning on development of downy mildew, powdery mildew, and cone yield. In each of the 3 years, two juxtaposed plots were established in each of 5 to 10 commercial hop yards planted to Nugget or Willamette, discussed in greater detail below. Each of the paired plots were five to six rows wide by the length of the hop yard, a total area of 0.5 to 2 ha depending on the size of the yard. Two pruning treatments were compared in these paired plots: a grower's standard pruning timing and a delayed pruning treatment. Due to the practicalities of conducting this research under commercial production conditions, the timing of the growers' standard pruning timing and delayed pruning timing varied among fields, with delayed pruning having occurred 10.2 \pm 5.0 days (range of 5 to 21 days) later than the standard pruning time. Other production inputs and cultural practices were applied identically to each of the plots, including the cooperating growers' standard fungicide applications for disease management. Therefore, the effect of pruning timing on downy mildew and powdery mildew was evaluated (as described above) when overlaid on the growers' other disease management tactics.

In 2007, the pruning treatments were applied in five hop yards, three of Willamette and two of Nugget. The pruning timing treatments also were applied to the same plots in these yards in 2008 and 2009 to evaluate multi-year effects of delayed pruning on yield and disease suppression. In 2008, the experiment was expanded and the pruning timing treatments were applied in an additional two yards of Willamette and three additional yards of Nugget. The plots in these hop yards also received the same pruning treatments in 2009. Thus, in total, there were 12 location-years for Nugget and 13 for Willamette. The experiment was a randomized complete block design, with blocking over farms within a year.

Levels of downy mildew (Willamette and Nugget) and powdery mildew (only for Willamette because Nugget is resistant to powdery mildew in the Pacific Northwest; 7) were assessed in each plot by sampling 100 plants in one row from each plot for incidence as described above. To assess the effect of pruning timing on each disease, RAUDPC was modeled to be a function of the independent fixed-effect variables pruning timing (standard versus delayed), year of sampling, and their interaction. These variables were considered fixed effects in the analysis. Hop yard was considered a random effect. Heterogeneous variances between delayed versus standard pruning timing groups were specified due to une- qual variances among pruning treatments (homogeneity of variance test $P \leq 0.02$ for powdery mildew and $P \leq 0.002$ for downy mildew). Significant differences between pruning timings within a year were determined by simple effect contrasts using the slicediff option in GLIMMIX.

At harvest, cone yield estimates were obtained from each plot by arbitrarily selecting 10 to 15 plants and harvesting the cones using a portable hop picking machine. The fresh weight of the cones for each plant was recorded, and then a subsample of cones was col-

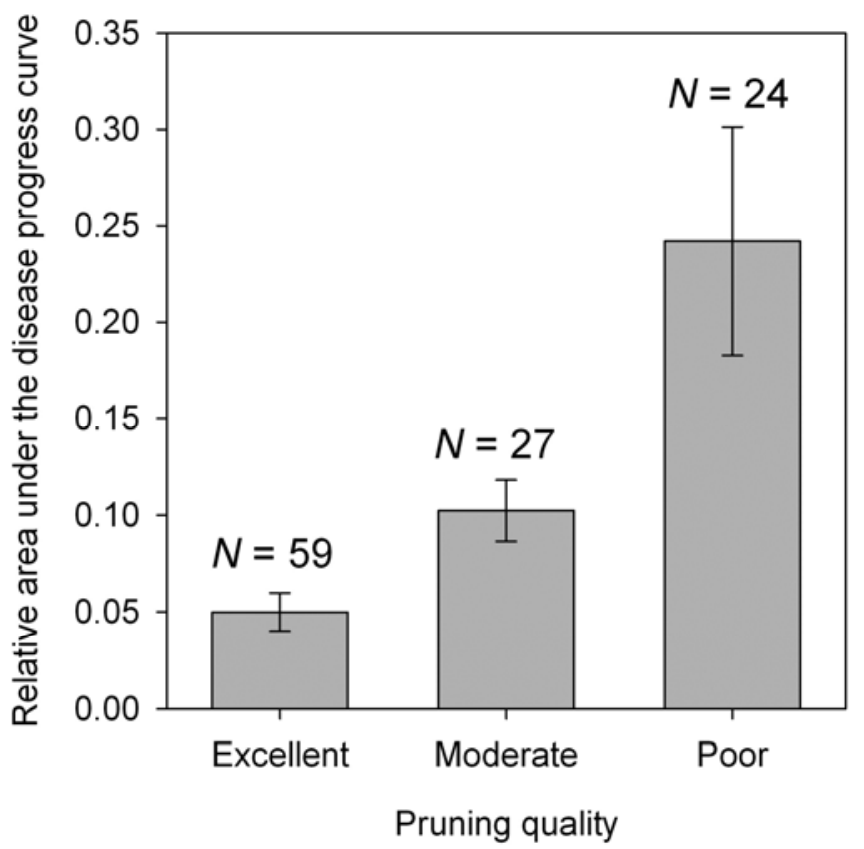

Fig. 2. Association of spring pruning quality to severity of downy mildew (caused by Pseudoperonospora humuli) on hop as determined from assessments conducted in 110 commercial hop yards in western Oregon during 2005 to 2010. Pruning quality was rated following the cooperating growers' pruning operation and classified as "excellent" if no green leaves of stems were present on any hop plants, "poor" if green tissue was remaining on every plant, and "moderate" otherwise. Means in each group are significantly different $(P=0.001)$, controlling for the fixed effect of year of sampling, based on a generalized linear mixed model analysis. Error bars indicate the standard error of the mean.
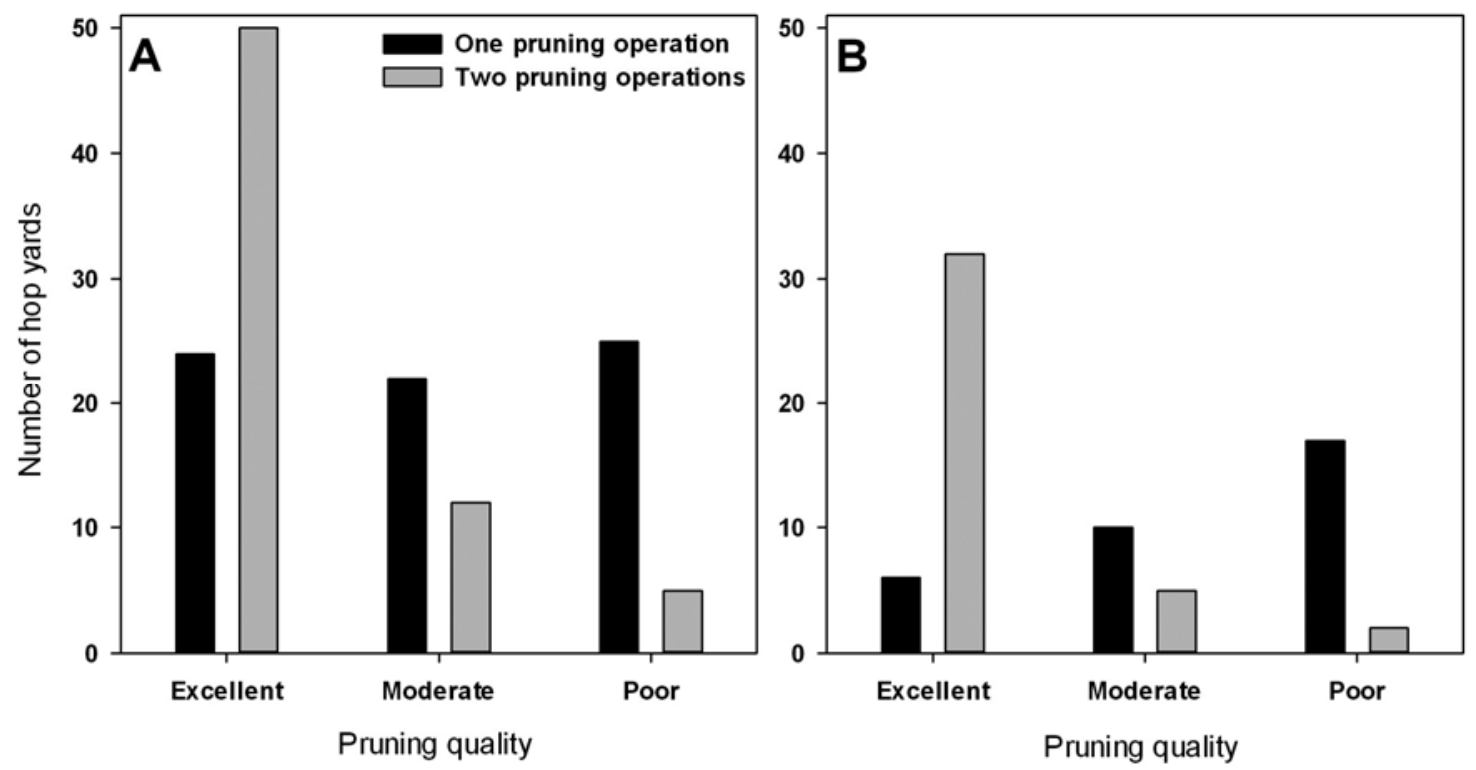

Fig. 1. Association of spring hop pruning quality to number of pruning operations conducted. Data are for $\mathbf{A}$, all pruning methods observed and $\mathbf{B}$, only chemical pruning. Pruning quality was rated following the cooperating growers' pruning operation and classified as "excellent" if no green leaves of stems were present on any hop plants, "poor" if green tissue was remaining on every plant, and "moderate" otherwise. In both analyses, pruning quality ratings were significantly associated with the number of pruning operations $\left(\chi^{2}\right.$ test, $\left.P<0.0001\right)$. 
lected to determine percent dry matter of the cones by drying the subsample in a drying oven for 48 to $72 \mathrm{~h}$ at $60^{\circ} \mathrm{C}$. This value was then used to standardize yields to dry weight per plant.

To standardize yield estimates across hop yards, mean yield (calculated from the 10 to 15 plants harvested individually per plot) of the plot receiving the delayed pruning treatment was expressed as relative to the yield of the plot that received the standard pruning timing. The mean difference in yield between treatments was analyzed for each cultivar and year by $t$ tests (unpaired, equal variance) using the TTEST procedure in SAS. Means were considered significantly different at $\alpha=0.05$ in a two-sided test.

\section{Results}

Association of pruning quality and method with disease severity. Spring pruning practices varied among the 149 hop yards surveyed (Table 1), although the most common approaches were chemical desiccation (48\% of yards), mechanical pruning (23\%), or a combination of these practices $(15 \%)$. No other pruning method was utilized in more than $4 \%$ of hop yards surveyed.

Pruning quality was rated as excellent, moderate, or poor in 51 , 25 , and $24 \%$ of the hop yards, respectively (Table 1 ). Regardless of pruning method, the distribution of pruning quality ratings was different in yards that were pruned once versus twice $\left(\chi^{2}=28.66\right.$, $P<0.0001)$. Among yards pruned once, the number of yards in each pruning quality category was similar whereas, for yards pruned twice, $75 \%$ of the yards were rated as having excellent pruning quality (Fig. 1A). The differences in pruning quality ratings were more pronounced for one versus two operations for chemical pruning $\left(\chi^{2}=31.01, P<0.0001\right)$. Among yards pruned by means of one chemical application, most yards (52\%) were rated poor whereas, for yards pruned twice chemically, most (82\%) were rated excellent (Fig. 1B).
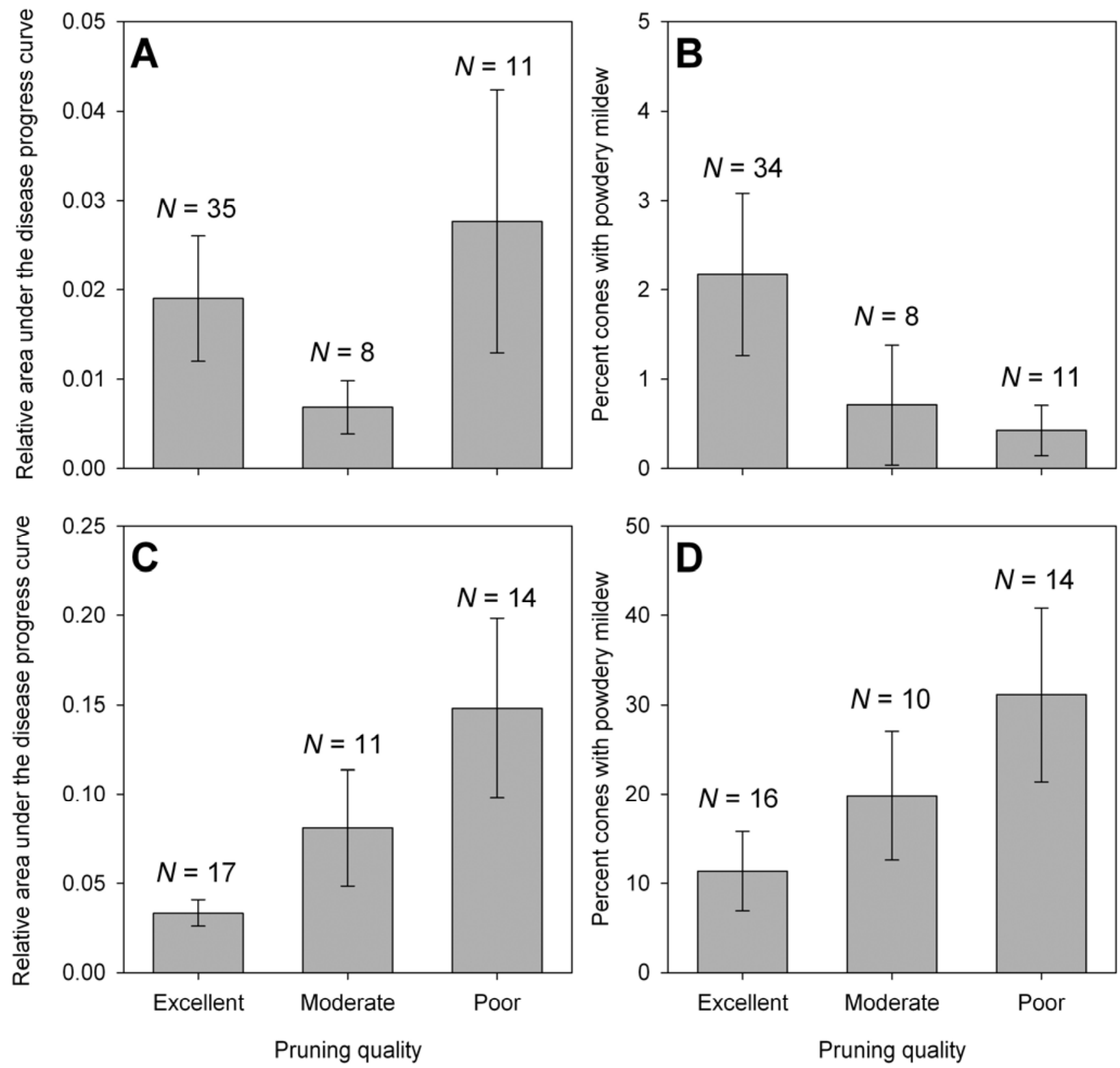

Fig. 3. Association of spring pruning quality to $\mathbf{A}$ and $\mathbf{C}$, seasonal severity of hop powdery mildew (caused by Podosphaera macularis) on leaves and $\mathbf{B}$ and $\mathbf{D}$, the incidence of cones at harvest with powdery mildew. Data are from $\mathbf{A}$ and $\mathbf{B}, 55$ commercial hop yards in Oregon and $\mathbf{C}$ and $\mathbf{D}, 42$ yards in Washington assessed for pruning quality and powdery mildew during 2000 and 2005 to 2010. The number of hop yards within a state evaluated for powdery mildew on leaves and cones varied by one yard in Oregon and two yards in Washington. Pruning quality was rated following the cooperating growers' pruning operation and classified as "excellent" if no green leaves of stems were present on any hop plants, "poor" if green tissue was remaining on every plant, and "moderate" otherwise. See text for an explanation of statistical analysis. Error bars indicate the standard error of the mean. 
Downy mildew. Over the 110 hop yards included in the analysis for downy mildew, mean RAUDPC increased progressively in yards that were rated as having excellent, moderate, and poor pruning quality (Fig. 2). In the mixed-model analysis, both year and pruning quality were significant factors $(F=4.52, P=0.001$ and $F$ $=7.86, P=0.001$, respectively). The means were significantly different between each of the pruning quality groups.

Powdery mildew. For powdery mildew on leaves, the fixed effect of pruning quality was not significant $(F=1.35, P=0.267)$ but year $(F=8.26, P<0.0001)$, state $(F=15.95, P<0.0001)$, and the interaction of pruning quality-state $(F=3.32, P=0.041)$ were significant. This indicates that pruning quality did not have an overall association with powdery mildew severity but, rather, the association of pruning quality with powdery mildew severity varied between Oregon and Washington. In Oregon, mean RAUDPC was relatively low (0.007 to 0.028$)$ among all pruning quality categories and did not vary significantly among the categories (Fig. 3A). Conversely, mean powdery mildew epidemic severity in Washington (Fig. 3C) increased in a stepwise progression in yards from excellent to poor pruning. Mean RAUDPC was significantly different between yards that received excellent versus poor pruning quality ratings (linear contrast $t=-2.57, P=0.012$ ).

The incidence of cones with powdery mildew followed a similar stepwise pattern as powdery mildew severity of leaves in Washington, although there was not an obvious association between these variables in Oregon (Fig. 3B and D). In the mixed-model analysis, state $(F=61.99, P<0.0001)$ and year $(F=11.22, P<0.0001)$ were significant factors, and there was a significant interaction of pruning-state $(F=3.13, P=0.049)$. In Oregon, there were no differences in the incidence of cones with powdery mildew associated with pruning quality. In Washington, the incidence of powdery mildew was significantly less in yards that had excellent pruning versus those with poor pruning (linear contrast $t=-2.21, P=$ 0.030).

Grower fungicide spray practices. Downy mildew. Yards that had excellent pruning received, on average, 1.1 to 1.5 fewer fungicide applications per year than yards with less thorough pruning (Table 2). This reduction in total fungicide applications was associated with a tendency for the first application to be applied later in the yards that had excellent pruning.

Powdery mildew. Similarly, for powdery mildew (averaged across both Oregon and Washington), yards that had excellent pruning were sprayed 1.1 to 1.5 fewer times than yards that had some foliage remaining after pruning (Table 2). Again, the tendency for fewer pesticide applications for powdery mildew in yards with excellent pruning quality was associated with a later timing of the first application.

Pruning timing study. Downy mildew. In Willamette, downy mildew severity was significantly affected by year of sampling $(F$ $=4.11, P=0.033)$ and pruning timing $(F=4.84, P=0.043)$, with only weak evidence for an interaction of year-pruning timing $(F=$ $3.28, P=0.063)$. Within a given year, pairwise contrasts showed that downy mildew severity was significantly reduced $(t=-4.16 ; P$ $=0.0002$ ) with delayed pruning compared with standard pruning in 2007, whereas pruning timing effects were nonsignificant in 2008 $(t=-0.65 ; P=0.528)$ and $2009(t=0.20 ; P=0.847)$ (Fig. 4A). In the more downy-mildew-susceptible Nugget, downy mildew severity was significantly affected by year of sampling $(F=8.19, P=$ $0.002)$ but not pruning timing $(F=0.00, P=0.950)$. This effect was consistent across years based on the nonsignificant interaction term (Fig. 4B; $F=0.17, P=0.848$ ).

Powdery mildew. Powdery mildew severity in Willamette varied among years $(F=6.80, P=0.014)$ but was not influenced significantly by pruning timing $(F=0.89, P=0.368)$. The lack of effect of pruning timing on powdery mildew severity was consistent across years based on the nonsignificant interaction term $(F=0.56$, $P=0.589 ;$ Fig. 4C).

Yield effects. In Willamette, yield differences between plots that received standard and delayed pruning were not significant $(P \geq$ 0.0786; Fig. 5A). However, in 2007 , yield was $8.4 \%$ greater in plots that received the delayed pruning treatment based on a onesided $t$ test $(P \geq 0.0393)$. Similarly. in Nugget, yield differences were not significantly different in any year $(P \geq 0.3453$; Fig. 5B). There was considerable variability in yield differences between the pruning treatments among hop yards, particularly in Willamette, which is evident by the large error bars associated with each mean (Fig. 5).

\section{Discussion}

The thoroughness of spring pruning practices appears to be a key consideration for managing powdery mildew and downy mildew on hop in the Pacific Northwest United States. The thoroughness of pruning had a similar qualitative association with the severity of downy mildew in Oregon and powdery mildew in Washington from field survey data. For both diseases, the mean relative severity of disease increased approximately twofold as pruning quality decreased. We note, however, that a similar stepwise increase in powdery mildew severity was not apparent in Oregon on either leaves or cones. This incongruence may be explained by the relatively low incidence of powdery mildew in Oregon during these studies (Fig. 3, note ordinate axis scales). The incidence of powdery mildew on hop leaves $(12,35,36)$ and cones (11) is lower in Oregon than Washington due, in part, to less successful perennation of $P$. macularis in Oregon because of more common use of mechanical pruning methods, production of generally less susceptible cultivars, and climate factors $(22,36)$. The powdery mildew fungus overwinters at a much lower frequency in Oregon than Washington, with flag shoots occurring on an average of $0.02 \%$ of plants in Oregon compared with $0.69 \%$ of plants in Washington (8). Consequently, powdery mildew does not occur in every hop yard in Oregon comprising susceptible cultivars $(6,8)$. The lack of an association between pruning quality and powdery mildew levels on leaves or cones, on average, in Oregon may arise from a somewhat random occurrence of powdery mildew among

Table 2. Association of grower fungicide application practices with spring pruning quality

\begin{tabular}{lcccc}
\hline & & & \multicolumn{2}{c}{ Mean value (standard error) $)^{\mathbf{a}}$} \\
\cline { 3 - 5 } Pruning quality $^{\mathbf{b}}$ & Number of yards & First application & Last application & Total applications \\
\hline Downy mildew & & & & \\
$\quad$ Excellent & 55 & $121.7(3.0)$ & $194.8(4.5)$ & $5.1(0.4)$ \\
Moderate & 27 & $109.8(3.3)$ & $201.2(4.1)$ & $6.6(0.5)$ \\
$\quad$ Poor & 22 & $114.2(4.9)$ & $192.4(7.0)$ & $6.2(0.8)$ \\
Powdery mildew & 44 & $142.5(2.6)$ & & $6.0(0.5)$ \\
Excellent & 15 & $130.7(3.1)$ & $212.2(3.7)$ & $7.1(0.7)$ \\
Moderate & 20 & $128.3(4.1)$ & $213.3(6.1)$ & $7.5(0.9)$ \\
Poor & & $211.1(5.7)$ & \\
\hline
\end{tabular}

${ }^{a}$ Fungicide application information was self-reported from cooperating growers. First and last application are day of year. Total applications are the number of times a spray was made in which at least one active ingredient with some activity against downy mildew or powdery mildew was applied.

b Pruning quality was rated following growers' pruning operation, and classified as "excellent" if no green leaves or stems were present on any hop plants, "poor" if green tissue was remaining on every plant, and "moderate" otherwise. Downy mildew data are from 104 hop yards in Oregon rated during 2005 to 2010. Powdery mildew data are from 50 hop yards in Oregon and 29 hop yards in Washington rated during 2000 and from 2005 to 2010. 
and within yards due to its lack of survival in most yards, obfuscating any association with pruning quality.

In Washington, where powdery mildew was more severe, an association between spring pruning quality and incidence of powdery mildew on cones was also detected. The incidence of powdery mildew on cones is known to be related to the incidence of disease on the leaves (36). The association of pruning quality to the incidence of cones with powdery mildew measured nearly 5 months later likely is an indirect effect linked to reduction of powdery mildew on leaves. A similar response would be expected in yards in Oregon where the powdery mildew fungus perennated successfully.

Pruning quality was generally associated with the number of pruning operations made, particularly for hop yards that received only chemical pruning. Variability in hill size and height during mechanical pruning often leaves shoots on the side or depressions of hills. In these studies, yards often received a pruning quality rating other than excellent because shoots on the sides of hills were not moved after pruning. Chemical pruning typically is conducted later than mechanical pruning in commercial production and, consequently, there tends to be more foliage present at the time of pruning. Apparently, the increased vegetative density often results in poor pruning quality when attempted using only one desiccant application. These traits provide reasons for the differences in pruning quality observed among pruning practices.

There are several plausible explanations for the association between pruning quality and epidemic severity observed in these studies. Because these studies were based on observational experiments, the observed associations may be simply correlated to other, unmeasured variables. One could conjecture that growers who are conscientious about pruning quality have fundamentally different farming practices than growers who practice less-thorough pruning. For instance, differences in pruning quality may reflect differences in more intensive use of fungicides or other crop management tactics. Although it is not possible to account for every unobserved variable in a correlative study, we investigated several potentially confounding effects tabulated from the grower production records. The variables we calculated indicate that, on average, growers with thorough pruning make fewer fungicide applications for both downy mildew and powdery mildew. For both diseases, this appears to be related to a later initiation of fungicide applications.

The association of pruning quality with the severity of downy mildew in Oregon and powdery mildew in Washington could be due to both direct and indirect effects. Indirect effects could include reduced susceptibility of foliage, cones, or both following thorough pruning or altered plant growth characteristics with different pruning intensities which, in turn, could affect canopy development and microclimate favorability to both diseases. Simpler explanations would be direct effects such as avoidance of disease-favorable weather $(9,23)$ or inoculum reduction. It seems very plausible that thorough pruning reduces or eliminates primary inoculum of Pseudoperonospora humuli and Podosphaera macularis. The first emergence of hop shoots with downy mildew is closely linked to heat accumulation and plant growth (9), and the first primary basal spikes emerge in most yards during late winter to early spring. Similarly, some powdery mildew flag shoots emerge in sync with resumption of annual shoot growth $(7,8)$. Therefore, inoculum of pathogens may be present at the time of pruning and the potential for localized inoculum to persist appears to be clearly linked to the amount of foliage remaining after pruning.

Other studies have noted that the amount and timing of primary inoculum appearance exert a great influence on powdery mildew and downy mildew outbreaks on hop $(9,15,17,27)$, as well as polycyclic diseases in other systems $(1,14)$. Epidemiological theory predicts that management of polycyclic diseases can be achieved by reducing initial disease intensity or the rate of disease increase (37). Sanitation measures such as pruning delay epidemic development and are predicted to have relatively modest effects with diseases with rapid rates of development and long epidemic durations (20). These are generally characteristic of downy mildew and powdery mildew on hop in the Pacific Northwest, and the large reduction in both downy mildew and powdery mildew severity

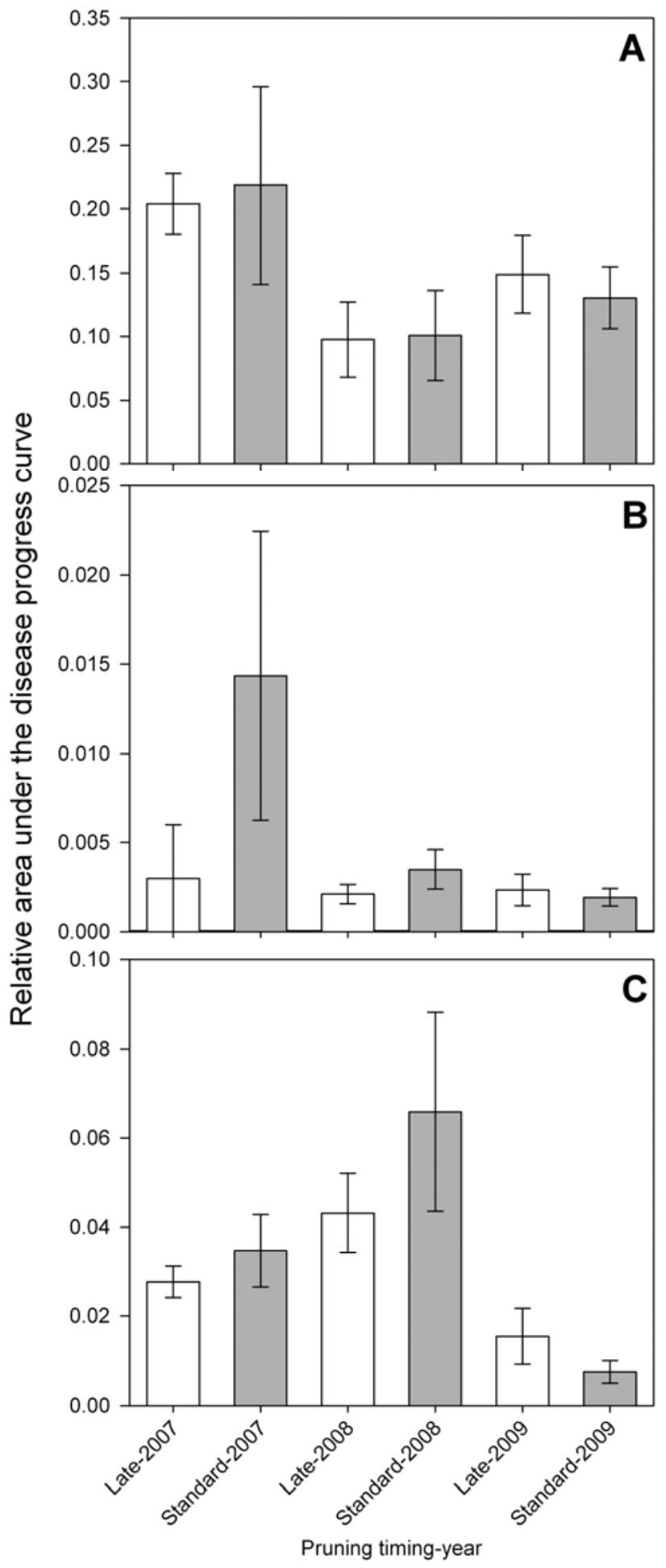

Fig. 4. Severity of $\mathbf{A}$ and $\mathbf{B}$, hop downy mildew (caused by Pseudoperonospora humuli) and $\mathbf{C}$, powdery mildew (caused by Podosphaera macularis) in relation to spring pruning timing. Data are from two to five hop yards per year of A, 'Nugget' and $\mathbf{B}$ and $\mathbf{C}$, 'Willamette', where pruning timing was compared in paired plots. Late pruning was conducted $10.2 \pm 5.0$ days later than the standard commercial pruning timing within a given hop yard. Controlling for the effect of year of sampling, downy mildew severity was significantly reduced by late pruning versus standard pruning in Willamette in 2007 (pairwise contrast $P=0.002$ ) based on a generalized linear mixed-model analysis. Other means were not significantly different $(P \geq 0.528)$ Error bars indicate the standard error of the mean. 
associated with a single sanitation measure applied early in epidemic development is noteworthy. The substantial reduction in downy mildew in Oregon and powdery mildew in Washington suggest that thorough pruning may remove a considerable proportion of the initial inoculum required for epidemic development. Additional experiments are needed to test this hypothesis.

The pruning timing studies indicate that delayed pruning timing, when overlaid on other commercial disease management tactics, can suppress downy mildew in some years in Willamette. Downy mildew was significantly reduced (fivefold compared with the standard pruning timing) in 1 of the 3 years of this study. During that year, pruning was delayed, on average, 6.3 days compared with the growers' standard pruning timing. Reductions in downy mildew were not observed on Nugget. This cultivar is more susceptible to downy mildew than Willamette (16), and the relative severity of downy mildew on Willamette (independent of pruning treatment) was 10 - to 20 -fold less than that of Nugget (Fig. 4). It is unclear whether the dissimilarity in cultivar susceptibility is the reason for the observed differences in pruning timing effects. Powdery mildew severity on leaves (Willamette) was not significantly affected which, again, may be related to the low incidence of powdery mildew in Oregon during these studies.

In both the pruning quality and pruning timing studies, year-specific effects due to weather were controlled for in the analysis by considering year a fixed effect to account for overall differences among years in disease severity. This means that each year potentially had a unique intercept term in the model, which could be due to differing weather favorability for each disease or other yearspecific variables that affected disease levels. Therefore, the treatment effects identified hold across all years but may not necessarily represent the disease levels for any single year. The interaction of pruning quality-timing-environmental factors on disease suppression warrants further investigation.

Although levels of downy mildew and powdery mildew were mostly unaffected by pruning timing in this study, there is value in delaying pruning simply to escape disease-favorable weather, particularly for downy mildew, and postpone the timing of the first fungicide application. The climate in western Oregon is characterized by cool, wet springs which can be favorable to downy mildew in some years (9). Temperature and, to a lesser extent, wetness can be limiting to downy mildew in this environment, although conditions favorable for infection may occur in early spring (9). Extended periods with temperature below $16^{\circ} \mathrm{C}$ and frequent rain events tend to suppress powdery mildew (22), both of which are common in western Oregon. In this work, pruning timing was delayed, on average, 10.2 days in the late-pruned plots, which could easily save one fungicide application per year. This savings is estimated conservatively at $\$ 90 /$ ha based on fixed and variable costs associated with a typical fungicide application (3). A principal consideration of whether such a strategy is advisable is the impact of later pruning timing on yield. We were unable to detect a significant effect of delayed versus standard pruning timing on yield across all yards, although differences within and among individual fields (based on individual plant harvests from the pair plots) were apparent, especially with Willamette. Yield responses due to pruning timing were variable in this cultivar, and may depend on (unspecified) yard-specific factors. Potential determinates of yield response due to pruning timing were investigated in other analyses not reported here, including specific pruning dates, yard age, and cumulative effects from multiple years of late pruning; none consistently explained the observed yard-to-yard variability. Further study is warranted to clarify the optimal pruning timing of this cultivar, which appears dependent on factors that vary at the scale of individual hop yards.

Several conclusions and recommendations for management of powdery mildew and downy mildew flow logically from this study. Thorough pruning is expected to significantly reduce the severity of powdery mildew and downy mildew when these diseases occur at appreciable levels, and achieving excellent pruning quality generally requires two pruning operations. This is particularly true for chemical pruning methods. Delaying pruning by 5 to 21 days from growers' current pruning practices can further contribute to suppressing downy mildew in Willamette. However, the impact of pruning timing on yield may be positive or negative and needs to be considered carefully based on yard-specific factors that remain poorly defined. More broadly, the current study also indicates that sanitation measures can be effective management approaches for polycyclic diseases, even those with rapid rates of development and long epidemic durations.

\section{Acknowledgments}

Funding for these studies was provided by the Agricultural Research Foundation, Hop Research Council, Oregon Hop Commission, Oregon State University, Washington Hop Commission, Washington State University, and USDA-ARS CRIS Projects 303-5358-22000-030-00D and 5358-21000-035-00. We thank D. Johnson and M. Twomey for helpful suggestions that improved the manuscript, the many individuals who assisted in disease assessments, and the hop growers who allowed us access to their farms for sampling and shared production records.
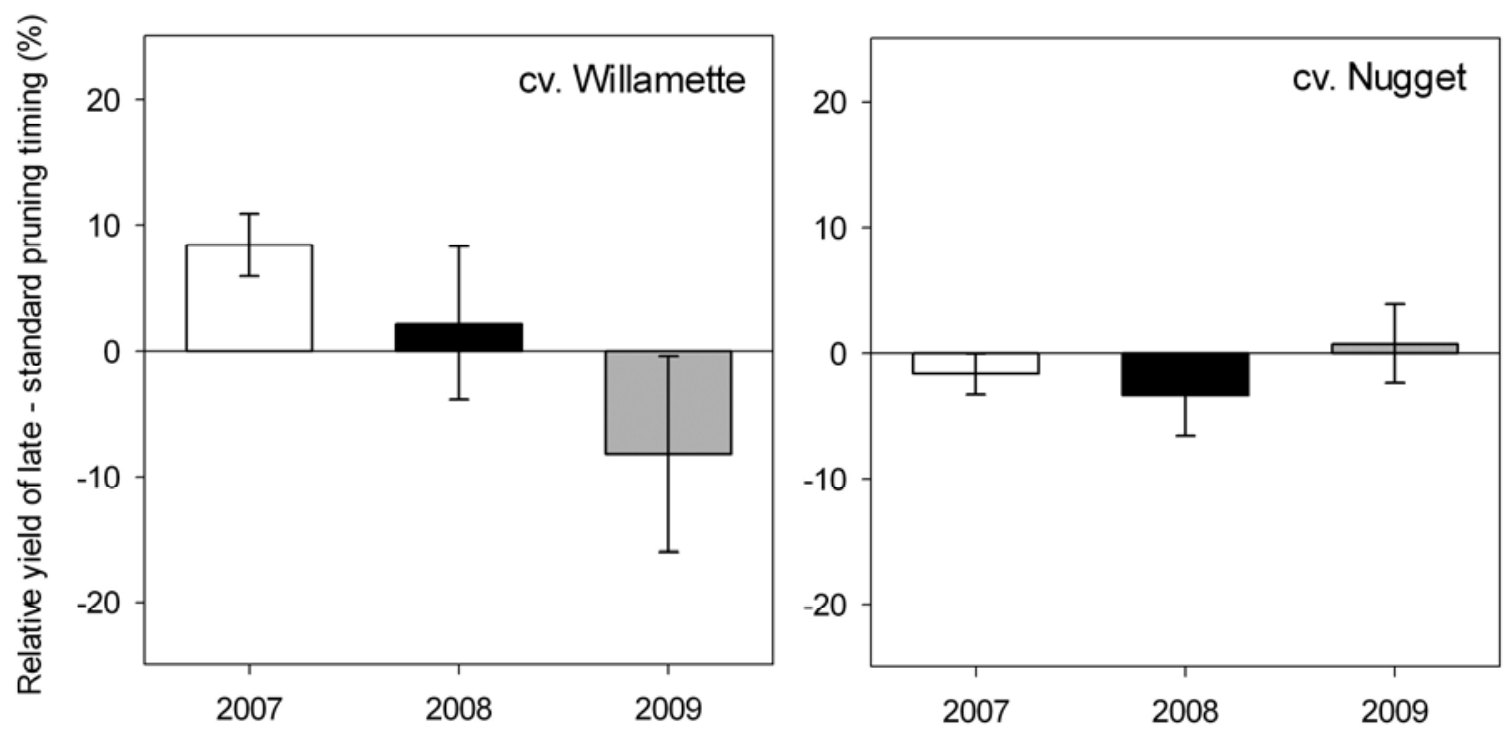

Fig. 5. Yield increase or decrease associated with pruning hop plants in spring 5 to 21 days later than the standard commercial pruning timing. Average yield responses are presented for paired plots in two to five hop yards per year of 'Willamette' and 'Nugget'. Mean yield differences between late and standard pruning are not significantly different than 0 for either Willamette or Nugget based on $t$ tests conducted within each year and cultivar ( $P \geq 0.079)$. Data are from 2007 (white bars), 2008 (black bars), and 2009 (gray bars). Error bars indicate the standard error of the mean. 


\section{Literature Cited}

1. Carisse, D., Tremblay, D-M., McDonald, M. R., Brodeur, L., and McRoberts, N. 2011. Management of Botrytis leaf blight of onion: the Québec experience of 20 years of continual improvement. Plant Dis. 95:504514.

2. Coley-Smith, J. R. 1965. Infection of hop rootstocks by downy mildew Pseudoperonospora humuli (Miy. et Tak.) Wilson and its control by earlyseason dusts. Ann. Appl. Biol. 56:381-388.

3. Galinato, S., George, A., and Hinman, H. 2011. 2010 Estimated Cost of Producing Hops in the Yakima Valley, Washington State. Wash. State Univ. Ext. Fact Sheet FS028E. Washington State University, Pullman.

4. Gent, D. H., Farnsworth, J. L., and Johnson, D. A. 2011. Spatial analysis and incidence-density relationships for downy mildew on hop. Plant Pathol. 61:37-47.

5. Gent, D. H., Lang, J. M, Bartolo, M. E., and Schwartz, H. F. 2005. Inoculum sources of Xanthomonas axonopodis pv. allii in Colorado. Plant Dis. 89:507-514.

6. Gent, D. H., Mahaffee, W. F., and Turechek, W. W. 2006. Spatial heterogeneity of the incidence of powdery mildew on hop cones. Plant Dis. 90:14331440.

7. Gent, D. H., and Nelson, M. E. 2010. Powdery mildew. Pages 18-21 in: Field Guide for Integrated Pest Management in Hops, 2nd ed. Washington State University, Pullman.

8. Gent, D. H., Nelson, M. E., George, A. E., Grove, G. G., Mahaffee, W. F., Ocamb, C. M., Barbour, J. D., Peetz, A., and Turechek, W. W. 2008. A decade of hop powdery mildew in the pacific northwest. Plant Health Progress. Online publication. doi:10.1094/PHP-2008-0314-01-RV

9. Gent, D. H., Ocamb, C. M., and Farnsworth, J. L. 2010. Forecasting and management of hop downy mildew. Plant Dis. 94:425-431.

10. Gent, D. H., Turechek, W. W., and Mahaffee, W. F. 2007. Sequential sampling for estimation and classification of the incidence of hop powdery mildew I: leaf sampling. Plant Dis. 91:1002-1012.

11. Gent, D. H., Turechek, W. W., and Mahaffee, W. F. 2007. Sequential sampling for estimation and classification of the incidence of hop powdery mildew II: cone sampling. Plant Dis. 91:1013-1020.

12. Gent, D. H., Turechek, W. W., and Mahaffee, W. F. 2008. Spatial and temporal stability of the estimated parameters of the binary power law. Phytopathology 98:1107-1117.

13. Goenia, A., and Micibski, B., 1972. The influence of term of rootstock cutting on the spring infestation of hop with Peronospora. Rocz. Nauk Roln. 2:7-22.

14. Johnson, D. A., Alldredge, J. R., and Vakoch, D. L. 1996. Potato late blight forecasting models for the semiarid environment of south-central Washington. Phytopathology 86:480-484.

15. Johnson, D. A., and Anliker, W. L. 1985. Effect of downy mildew epidemics on the seasonal carryover of initial inoculum in hop yards. Plant Dis. 69:140-142.

16. Johnson, D. A., Engelhard, B., and Gent, D. H. 2009. Downy mildew. Pages 18-22 in: Compendium of Hop Diseases and Pests. W. F. Mahaffee, S. J. Pethybridge, and D. H. Gent, eds. American Phytopathological Society, St. Paul, MN.

17. Johnson, D. A., Skotland, C. B., and Alldredge, J. R. 1983. Weather factors affecting downy mildew epidemics of hops in the Yakima Valley of Wash- ington. Phytopathology 73:489-493.

18. Littell, R. C., Milliken, G. A., Stroup, W. W., Wolfinger, R. D., and Schabenberger, O. 2006. SAS for Mixed Models. SAS Institute Inc., Cary, NC.

19. Liyanage, A. de S., and Royle, D. J. 1976. Overwintering of Sphaerotheca humuli, the cause of hop powdery mildew. Ann. Appl. Biol. 83:381-394.

20. Madden, L. V., Hughes, G., and van den Bosch, F. 2007. The Study of Plant Disease Epidemics. American Phytopathological Society, St. Paul, MN.

21. Mahaffee, W. F., Pethybridge, S. J., and Gent, D. H., eds. 2009. Compendium of Hop Diseases and Pests. American Phytopathological Society, St. Paul, MN.

22. Mahaffee, W. F., Thomas, C. S., Turechek, W. W., Ocamb, C. M., Nelson, M. E., Fox, A., and Gubler, W. D. 2003. Responding to an introduced pathogen: Podosphaera macularis (hop powdery mildew) in the Pacific Northwest. Plant Health Progress. Online publication. doi:10.1094/PHP-20031113-07-RV

23. Mahaffee, W. F., Turechek, W. W., and Ocamb, C. M. 2003. Effect of variable temperature on infection severity of Podosphaera macularis on hops Phytopathology 93:1587-1592.

24. Maloy, O. C. 1993. Plant Disease Control: Principles and Practice. John Wiley and Sons, New York.

25. Neve, R. A. 1991. Hops. Chapman and Hall, London

26. Palti, J. 1981. Cultural Practices and Infectious Crop Diseases. Springer Verlag, Berlin, Heidelberg, New York.

27. Royle, D. J. 1978. Powdery mildew of the hop. Pages 281-409 in: The Powdery Mildews. D. M. Spencer, ed. Academic Press, London.

28. Royle, D. J., and Griffin, M. J. 1973. Side-effects of downy mildew fungicides on the incidence of hop powdery mildew (Sphaerotheca humuli) Plant Pathol. 22:129-133.

29. Royle, D. J., and Kremheller, H. TH. 1981. Downy mildew of the hop. Pages 395-419 in: The Downy Mildews. D. M. Spencer, ed. Academic Press, New York.

30. Rybáček, V., ed. 1991. Hop Production. Elsevier Science Publishing Company, New York.

31. Savary, S., Mila, A., Willocquet, L., Esker, P. D., Carisse, O., and McRoberts, N. 2011. Risk factors for crop health under global change and agricultural shifts: a framework of analyses using rice in tropical and subtropical Asia as a model. Phytopathology 101:696-709.

32. Skotland, C. B. 1961. Infection of hop crowns and roots by Pseudoperonospora humuli and its relation to crown and root rot and overwintering of the pathogen. Phytopathology 51:241-244.

33. Skotland, C. B., and Johnson, D. A. 1983. Control of downy mildew of hops. Plant Dis. 67:1183-1185.

34. Thurston, H. D. 1990. Plant disease management practices of traditional farmers. Plant Dis. 74:96-102.

35. Turechek, W. W., and Mahaffee, W. F. 2004. Spatial pattern analysis of hop powdery mildew in the Pacific Northwest: implications for sampling. Phytopathology 94:1116-1128.

36. Turechek, W. W., Mahaffee, W. F., and Ocamb, C. M. 2001. Development of management strategies for hop powdery mildew in the Pacific Northwest. Plant Health Progress. Online publication. doi:10.1094/PHP-2001-0313-01RS

37. Vanderplank, J. E. 1963. Plant Diseases: Epidemics and Control. Academic Press, New York. 